\title{
Arlindo Machado en Argentina: lecturas, impulsos y líneas de fuerza
}

Arlindo Machado in Argentina: readings, drives and lines of force

Eduardo A. Russo ${ }^{1}$

\footnotetext{
${ }^{1}$ Director del Doctorado en Artes de la Facultad de Artes, Universidad Nacional de La Plata -Argentina-. Profesor de Teorías del Audiovisual y Análisis \& Crítica, Facultad de Artes, Universidad Nacional de La Plata. E-mail: earusso@fba.unlp.edu.ar
} 
Resumen: Este artículo traza un panorama sobre el impacto de la obra de Arlindo Machado en el ámbito académico y cultural argentino, a partir de la traducción de sus trabajos al castellano y sus actividades curatoriales y de enseñanza, desde inicios de los años 1990. Se detectan líneas de fuerza del itinerario de Machado, con sus reconocidas incursiones en el campo de la creación fotográfica, sus experiencias en el cortometraje y obras multimediales, sus libros electrónicos en distintas arquitecturas y formatos y las publicaciones que han dejado marcas notables no solo en Argentina, sino también en otros países de América Latina. Palabras clave: Arlindo Machado; arte; cine; video; nuevos medios.

Abstract: This article outlines the impact of Arlindo Machado's work on Argentina's academic and cultural sphere from the translation of his texts into Spanish and his teaching and curatorial activities since the early 1990s. The lines of force of Machado's itinerary are detected, with his recognized forays into the field o photographic creacion, his experiences in short films and multimedia works, his electronic books in differents architectures and formats, and the publications that have left notable marks, not only in Argentina, but also in other Latin American Countries.

Keywords: Arlindo Machado; arts; film; video; new media. 


\section{Una voz distintiva}

A inicios de los años 1990, la traducción al español de los trabajos de Arlindo Machado era incipiente y fragmentaria, con la circulación de algunos ensayos esparcidos en publicaciones académicas de América Latina. Por ejemplo, su texto clave "El imaginario numérico: simulación y síntesis" se publicó en Acta Poética, la revista del Instituto de Investigaciones Filológicas de la Universidad Nacional Autónoma de México (MACHADO, 1992). Rodeada por artículos diversos en un número dedicado a las semióticas no verbales, asomaba una voz diferente y reacia a los encuadres disciplinares, que ejercía una mirada transversal sobre un radical cambio de régimen cuyo alcance pocos llegaban aún a vislumbrar. A partir del concepto que había perfilado Alain Renaud para encarar un territorio que muchos consideraban como una novedad básicamente instrumental, Machado analizaba un nuevo foco de atención para el arte, la tecnología y la comunicación. Se trataba de un objeto, además, que obligaba a repensar la configuración y las delimitaciones de esos ámbitos, planteando la emergencia de un nuevo régimen de lo visible y una reconfiguración tanto del mundo percibido o inteligido como de la subjetividad contemporánea. El texto, en una formulación cristalina, dejaba en evidencia que su autor avistaba un territorio de difícil inscripción en las especializaciones habituales del campo académico y, a la vez, de largo aliento.

Simultáneamente a la circulación ocasional en publicaciones universitarias hispanohablantes de alcance internacional, en pequeña escala, en Buenos Aires se estaba gestando un sistemático polo de difusión en castellano para los trabajos que Machado llevaba más de una década publicando en portugués. Con el inicio de una serie de publicaciones ideada por Jorge La Ferla, los Video Cuadernos, estrechamente relacionadas con su actividad docente en la Universidad del Cine, una voz singular, dedicando espacio al lenguaje del video (MACHADO, 1991) y a la obra de la videasta Sandra Kogut (MACHADO, 1993), comenzó a ser reconocida por lectores argentinos, principalmente estudiantes de cine y artistas de diversos ámbitos que encontraron una guía para sus primeros acercamientos a la videocreación.

A lo largo de los años 1990, primero con los Video Cuadernos y, luego, con otras publicaciones compiladas por La Ferla, que cada año acompañaban a esa excepcional puesta al día que fue la Muestra Euroamericana de Cine, Video y Arte Digital (MEACVAD), una compacta serie de publicaciones colectivas y un par de volúmenes individuales propiciarían una notoria repercusión de la producción de Machado. Este proceso le permitiría gozar de un espacio propio, divergente y 
alternativo respecto de las tradiciones disciplinares y las compartimentaciones territoriales al uso de departamentos, facultades y áreas de estudio universitarios. Fue creciendo así una instalación tan intersticial como firme en el campo académico e intelectual de más un cuarto de siglo en castellano. A partir de las traducciones de sus textos y sus reiteradas actividades en la Argentina, se expandió una nítida influencia conceptual, que también se convirtió en un impulso para la producción teórica, crítica y artística, a la vez que incidió fuertemente en el campo de las actividades curatoriales. Por otra parte, este foco que en un tramo inicial fue activado particularmente desde Argentina contribuyó, en el curso de dos décadas, al establecimiento de una verdadera red que generó iniciativas de investigación, enseñanza y actividades curatoriales crecientes a escala latinoamericana, en las cuales la figura de Machado se afirmó como referencia indiscutida.

En el número 56 de la revista Significação, Marcus Bastos ha señalado con perspicacia en el pensamiento de Machado la existencia de una doble vía de acercamiento al arte, la comunicación y los medios, ejercida en dos sentidos complementarios. Por una parte, cuando se abordaba medios con una tradición teórica más o menos desarrollada, Machado se ocupaba de desmontar los lenguajes y proponer originales alternativas a las ideas establecidas. Así es posible advertir que al tratar a la fotografía, al cine o a la televisión, entablaba una discusión firme, y no exenta de algunas asperezas, con ciertos referentes habituales del área, incluso refutaba enérgicamente algunos monstruos sagrados. No lo hacía meramente por afán polémico, sino guiado por la necesidad de elaborar un pensamiento que no se amparase en el argumento de autoridad. De lo contrario, buscaba fundarse en la búsqueda de la propia consistencia. Como complemento a ese discurso combativo, que demolía lo previamente consensuado -muy especialmente cuando dichas ideas recibidas se fundaban en juicios totalizadores y desprovistos de un examen serio de la experiencia de los medios- Machado también tenía interés en detectar y cartografiar, en la medida de lo posible, algunos ámbitos y lenguajes emergentes. De ese modo, su temprana atención puesta en ascendente videoarte en los años 1980, que luego amplió a la constelación abierta por los nuevos medios en el giro digital hicieron posibles verdaderos mapas provisionales y guías de ruta para la comprensión de fenómenos tan novedosos como complejos (BASTOS, 2021).

Hemos estado a punto de aludir, como título de este artículo, a la recepción de la obra de Arlindo Machado en la Argentina. Pero designar como un fenómeno de recepción lo ocurrido en su caso tal vez nos haga incursionar en un error. Podríamos afirmar que, en rigor, no se trató de una recepción, como tampoco 
fueron exactamente receptores los sujetos interpelados por los textos, las clases o charlas de Machado; más bien hubo, y hay interlocutores, sujetos impactados por su discurso y promovidos a prolongar sus contribuciones por medio de una acción que acepta el desafío y se dispone a continuar la búsqueda. En un panorama donde el encorsetamiento disciplinar, por una parte, y las rutinas de pensamiento y los tan requeridos "marcos teóricos" que reproducían ciertas liturgias delimitaban los intentos de comprensión de la relación entre arte y medios, la irrupción de los trabajos de Machado fue altamente removedora de un cúmulo de lugares comunes esgrimidos como teoría. Su obra estimuló la apertura de un área que combinaba los intereses por el audiovisual con una preocupación más abarcadora sobre las relaciones entre tecnologías y sujetos, y exploraba con audacia los desafíos de una profunda transformación en curso.

Machado desafiaba ciertos discursos empeñados en reproducir obedientemente lo previamente estatuido, por una parte, desde algunas ciencias sociales o del campo de las ciencias de la comunicación, contribuyentes al núcleo de los estudios sobre medios. Por otra parte, también manifestaba otras zonas de disidencia con autores o ideas provenientes de distintos sectores de las humanidades, como las tradicionales historias del arte, los estudios orientados al examen de la cultura visual, o bien la estética, la teoría y la historia del cine que se apilaba en forma de libros y escritos. Opuesto a los frentes disciplinarios y sus identidades monolíticas, Machado proponía una discusión que se mantenía abierta al diseño de un aparato conceptual ad hoc para la intelección de las encrucijadas que planteaban las relaciones entre arte, tecnología y comunicación. A su modo, más que un teórico en un sentido consumado, poseedor de modelos acabados, era alguien empeñado en diseñar y rediseñar su propia caja de herramientas conceptual a partir de una incesante actividad analítica y crítica, ya que leía en la creación audiovisual tantas ideas como las que encontraba en letra impresa. Resulta muy sintomático observar que entre aquellos impactados por su producción a lo largo de su itinerario en la Argentina se encuentren no pocos artistas, arquitectos y diseñadores. Su misma experiencia en el campo de la creación visual y sus actividades curatoriales lo apartaban de un ejercicio teórico o analítico cerrado sobre la elaboración de su discurso, y lo insertaban en una matriz dialogal que excedía la comunidad de investigadores, para extenderse entre otros perfiles de practicantes del arte y la comunicación.

Resulta altamente sugestivo que entre los autores en los cuales Machado fundaba algunas de sus ideas más audaces estuvieran referentes históricos que fueron decididamente refractarios a los intentos de clasificación disciplinar y académica, 
como Mijail Bajtin, Walter Benjamin, Gilbert Simondon y Vilém Flusser. Junto a ellos, resulta fundamental agregar la figura acaso aún más inclasificable y desbordante de Sergei Mijáilovich Eisenstein, a quien dedicara su primer libro en 1982 y que fuera una presencia siempre cercana en su discurso. El escritor no pocas veces también se revelaba como un sagaz lector de los aportes de sus referentes y ofertaba su producción para que lo suyo se inscribiera, a su vez, en la experiencia de sus lectores. De hecho, sus escritos han sido un elemento crucial, por citar solo un ejemplo, en la difusión del pensamiento de Vilém Flusser en la Argentina a inicios de este siglo, muy particularmente a partir de su indispensable "Repensando a Flusser y la imagen técnica" (MACHADO, 2001).

Trataremos, a continuación, de trazar algunos recorridos y repercusiones de sus textos, examinando cómo se convirtieron en disparadores de importantes iniciativas en el ámbito académico e intelectual, para detectar, finalmente, algunas líneas de fuerza de una obra que ha dejado marcas notables, aunque hasta hoy ha sido solo parcialmente volcada al castellano. Producción que, como lo ha destacado Lucia Santaella (2021), mantiene una vigencia pasmosa, especialmente en el campo de los nuevos medios, donde el vértigo de los acontecimientos suele desactualizar rápidamente los intentos de análisis y conceptualización.

\section{Lecturas, ideas e impulsos}

Examinemos más de cerca la expansión del influjo de la obra de Machado en castellano. Luego de los dos Video Cuadernos ya citados, que albergaron esos primeros textos suyos en Buenos Aires, La Ferla compiló en 1994 el primer volumen íntegramente compuesto por textos del autor como número VI de la serie. Como su compilador indicaba en el prólogo, esta publicación organizaba un conjunto de escritos tan breve como representativo. Para entonces, con esa pregnancia de las pequeñas publicaciones que pasaban de mano en mano y se replicaban "de manera clandestina en escuelas de cine y video, universidades y diferentes círculos multimediáticos del país" (MACHADO, 1994, p. 5) se afirmaba el reconocimiento.

El volumen reunía siete textos escritos por Machado en la década anterior que revelaban el espectro de intereses y elucidaciones propio de un autor muy difícil de adscribir a una pertenencia disciplinar o a un objeto de conocimiento predominante. El primer texto titulado "La cultura de la vigilancia" (1994) desafiaba los lugares comunes sobre la sociedad del espectáculo y planteaba una conceptualización alternativa, orientada a detectar la emergencia de una sociedad de vigilancia. Sin referirlo de manera central, resonaban en esta aproximación tanto 
el diagnóstico sobre las sociedades de control formulado por Gilles Deleuze como anticipaban lo que más adelante sería denominado de similar modo por autores como David Lyon. Pero ante todo las ideas de Machado eran desplegadas a partir de la lectura de un video clave: el documental Der Riese (1983), de Michael Klier. Más tarde fue posible leer a ese artículo, ya titulado como "Máquinas de vigilar", como una aproximación visionaria a un entorno regulado por máquinas de visión artificial, dedicadas al control de espacios y sujetos crecientemente desprovistos de toda privacidad. Allí se enmarcaba una gama de preocupaciones que desbordaba todo centramiento en un medio específico.

En su lugar, Machado proponía un acercamiento transversal a tecnologías de video, a los discursos cinematográfico y televisivo, a las culturas mediadas por máquinas de visión, pero también ingresaba en un análisis de ambición inusual sobre un nuevo entorno de carácter psicosocial y civilizatorio. El pequeño volumen proseguía con iluminadores ensayos sobre el zapping como maniobra mucho más compleja que el mero síntoma televisivo al que se lo reducía, sobre los noticieros en tiempos de la Guerra del Golfo y sobre los diálogos entre los discursos del cine y el video, más un análisis sobre la producción de grupos de videocreación en Brasil y el ensayo sobre el imaginario numérico que ya referimos. Este último texto, tan conciso como de alto impacto por su solidez teórica para encarar un tema emergente, se convertiría en un elemento clave en ese entonces para discutir la irrupción digital en un contexto que, abarcando el campo audiovisual, se expandía hacia una reconfiguración radical de un régimen de lo sensible y lo imaginable (MACHADO, 1994).

Hemos destacado en esta presentación la singularidad de la voz de Machado y la dificultad de asimilarlo a corrientes u orientaciones predominantes, especialmente aquellas relacionadas con los estudios sobre comunicación. Pero es preciso tomar en cuenta, por otra parte, que no era exactamente un solitario, ya que sus aportes guardan sintonías con los de otros pares que compartieron también en la misma época diversas visitas a la Argentina y contaron con algunas de sus obras clave publicadas. Las referencias recurrentes en sus acercamientos a la fotografía, la creación en video, las culturas y técnicas de la mirada y la escucha examinadas en tiempos largos, desde el precine hasta al postcine permitieron generar un diálogo en red que se transfirió desde los autores mencionados a una creciente comunidad horizontal, no exenta de discusiones, cuya tarea de correlacionar distintas experiencias del campo de la imagen y los medios fue una marca distintiva.

De ese modo, en conexión y discusión con las contribuciones de Raymond Bellour, Philippe Dubois, Siegfried Zielinski y Jean-Louis Comolli, los textos de 
Machado llegaron a ser parte habitual en las bibliografías de grado y posgrado de diversas universidades y centros de estudio en la Argentina. Fundamentalmente fue el permanente vínculo con La Ferla lo que hizo de Machado una presencia reiterada en las aulas locales durante casi dos décadas, mediante la participación en jornadas y muestras, así como en diversos seminarios y clases magistrales, en ocasiones extendidas en otras universidades argentinas. Las distintas ediciones de la MEACVAD vieron, en los libros colectivos presentados en cada año, los textos de Machado que se agregaban a un corpus creciente (MACHADO, 1996a, 1996b, 1996c, 1997a, 1997b, 1999, 2000a, 2000b, 2001, 2008a) y dialogaban de alguna manera con los autores mencionados. Cabe destacar que, entre todos ellos, lo distintivo de Machado consistía en el sostén de una mirada en la que, sin hallarse el menor registro de un latinoamericanismo declamatorio, se detectaba una impronta inequívocamente latinoamericana. En el "Prólogo" a la obra El paisaje mediático: sobre el desafío de las poéticas tecnológicas (MACHADO, 2000a), La Ferla afirmaba sin rodeos: "lo consideramos el mayor teórico sobre medios audiovisuales de nuestro continente".

La publicación de este libro marcó un verdadero hito, y dos décadas más tarde sería considerado en las aulas argentinas como un joven clásico en los estudios sobre artes audiovisuales, medios y tecnología. Fue una edición antológica preparada especialmente para la Argentina, larga aspiración de La Ferla durante los años precedentes. Machado seleccionó una serie de textos procedentes de varios libros: A arte do vídeo (1988), Máquina e imaginário (1993), Imaginário numérico (1995), Pré-cinemas e pós-cinemas (1997) y A televisão levada à Sério (2000). Además, incorporó casi completamente el contenido de O quarto iconoclasmo e outros ensaios hereges (2001), que sería publicado poco después, en abril de 2001, en Río de Janeiro.

En el prólogo que hemos tenido el placer de redactar para El paisaje mediático, y que gracias a la generosidad de Machado se convirtió poco más tarde en el posfácio de O quarto iconoclasmo e outros ensaios hereges, destacábamos cómo el autor desplegaba un abordaje, una metodología y hasta un tono comunicativo que lo alejaban simultáneamente de las teorizaciones nebulosas de los especialistas que profetizaban en el entorno medial una catástrofe inminente, haciendo de su discurso un símil de las trompetas del apocalipsis, y de los discursos celebratorios de quienes auguraban un estado angelical de comunión completa a cargo de las nuevas tecnologías comunicativas. En su heterodoxia, Machado no se ubicaba sobre los medios, visualizando todo desde una academia omnicomprensiva. Tampoco se lo advertía afecto a la ensoñación o a la pesadilla avistada desde las teorías grandilocuentes, rehuía a la tecnofobia y a la tecnofilia. Nada había en él 
de aquella figura del viajero sobre el mar de nubes que hechizase a Carl Gustav Carus, sino que más bien se lanzaba gozosamente a una jungla cerrada y proliferativa, intentando orientarse y trazar algunos senderos (RUSSO, 2000).

Entre la docena de libros colectivos compilados por La Ferla en la Argentina entre 1996 y 2008, once volúmenes cuentan con su aporte. A ello hay que sumar otra publicación fundamental, como el imponente volumen El medio es el diseño audiovisual (LA FERLA, 2007b), editado en Colombia por la Universidad de Caldas. Este libro constituye una verdadera summa sobre el estado de situación del pensamiento audiovisual a inicios del nuevo siglo y brinda la medida cabal de una presencia tan sostenida y desde distintos ángulos, ya que cuenta con nada menos que siete escritos de Machado, repartidos en diversos ejes que contiene el libro. Ese conjunto de textos colectivos en que su presencia fue determinante, junto con los dos volúmenes en solitario ya mencionados, Video cuadernos $I V$ y El paisaje mediático, cuyo éxito llevó a una segunda edición (MACHADO, 2009b), configuró un corpus de particular contundencia.

La estrategia antológica de dichas publicaciones, fuera en las obras colectivas o en los volúmenes que compilaron textos suyos de diversa procedencia, dispuso temas en un abanico que, tomando un término caro a Machado como lo es el de repertorio, permitía verificar la variedad y la insistencia de sus campos de interés. Estaban el cine o la televisión, tomados desde ángulos que desafiaban las modalidades usuales de los film studies o los media studies. También se frecuentaba el advenimiento de los nuevos medios y las derivaciones de lo digital, el videoarte, la creación artística y las máquinas, o las transformaciones del sujeto implicado en el trato con tecnologías de la mirada y la escucha, todos esos campos no solo se frecuentaban con solvencia y erudición, sino que no pocas veces establecían novedosas interconexiones.

La cuestión del repertorio, respecto de la televisión o la producción videográfica brasileña, fue una preocupación que se sostuvo constantemente en Machado. Repertorio, más que una cuestión de canon, esa construcción preferente de la academia y la crítica anglosajona, con sus resonancias modélicas. Se trata, en el repertorio, de un conjunto ligado por una exigencia de amplitud y variedad en su conformación, que corre a la par de cierta consistencia. A través de este concepto, el autor combatió la política de indiferenciación que acechaba tras la remanida apelación a un flujo televisivo, reduccionismo del que no era tan responsable Raymond Williams, sino sus lectores apresurados. Su estrategia era detener el flujo, hacer pausa para mejor apreciar ciertos pasajes destacados; observar las correlaciones y las diferencias entre la imagen en marcha y la detención en un instante o la serialización de algunos momentos. 
En este sentido, acaso Machado fue en América Latina quien más pudo aprovechar la dimensión analítica del poder espectatorial que se hizo posible gracias a la función tan humilde como decisiva del telecomando en el televisor y la videograbadora. Un espectador habilitado a un control sobre la imagen, que abrió el camino a nuevas instancias tanto de goce como de posibilidad de conocimiento. Autores cercanos a su perspectiva como Raymond Bellour, Jacques Aumont y Peter Greenaway han destacado en repetidas oportunidades el potencial del control remoto de activar una mirada topológica, dentro y fuera de la fascinación por la imagen móvil, que no podía dejar de conducir a nuevas fronteras para el estudio de los medios audiovisuales. En el análisis televisivo, en lugar de conjeturar presuntas tendencias o lineamientos generales, Machado se lanzó a un trato cuerpo a cuerpo con el noticiero y con el videoclip, que desafió un cúmulo de clichés o generalizaciones abusivas, planteando la citada cuestión del repertorio como un asunto crucial. Es plausible que en este asunto se activaran estrategias de lectura y ordenamiento muy cercanas a los procedimientos curatoriales que desarrollaba en paralelo con sus investigaciones; ver y entender mejor, y hacer ver y entender a otros, como parte de una misma experiencia.

Lo antedicho no significa que Machado prefiriera las ideas de corto alcance, sin aspirar al trazado de algunas conexiones de largo aliento. La apelación a las poéticas tecnológicas que había madurado en tiempos de Máquina e imaginário tiene un lugar destacado, que incluso se eleva al mismo subtítulo de El paisaje mediático: sobre el desafío de las poéticas tecnológicas. Desde los medios, el autor derivaba hacia las posibilidades transgénicas de la creación artística, a partir de un pormenorizado análisis de las experimentaciones de Eduardo Kac, en un camino que conducía hacia un horizonte transhumanista. De esa manera, su influjo fue altamente perceptible en diversas instituciones argentinas que en los últimos veinte años han desarrollado iniciativas de enseñanza e investigación en el campo del diseño y la comunicación, las artes electrónicas y audiovisuales.

Sin pretender un recuento exhaustivo de los emprendimientos donde se verifica su huella, podemos citar -además de la ya mencionada presencia de sus materiales en diversas cátedras, proyectos y planes de estudio de distintas facultades de la Universidad de Buenos Aires y la Universidad del Cine- diversos núcleos donde su enseñanza se ha traducido, más allá de su utilización como insumo bibliográfico, en lineamientos de diversas investigaciones y proyectos de tesis. Entre ellos es posible mencionar en particular a las carreras de grado y posgrado de la Facultad de Arquitectura, Diseño y Urbanismo de la Universidad de Buenos Aires, en las que las carreras de Diseño Gráfico y Diseño de Imagen y Sonido han contado con 
su aporte reiterado, y muy en particular la Maestría en Diseño Comunicacional, gracias al permanente vínculo con La Ferla. En la Universidad Nacional de La Plata, las Facultades de Artes y de Periodismo y Comunicación Social han incorporado sus materiales a distintas asignaturas desde los tiempos iniciales de su difusión local, y podría afirmarse que la influencia del pensamiento de Machado ha sido tan decisiva en la Facultad de Artes para inspirar diversos aspectos del actual diseño de la Licenciatura en Artes Audiovisuales, como previamente ocurrió en el surgimiento de la Licenciatura en Multimedia, hacia fines de los años 1990. También puede destacarse su influencia en diversas asignaturas, proyectos y actividades curatoriales realizadas en la Universidad Nacional de Tres de Febrero, especialmente en la Licenciatura y la Maestría en Artes Electrónicas.

Por otra parte, debe señalarse el significativo caso de Ludion, el colectivo de investigación sobre tecnopoéticas fundado por Claudia Kozak, que viene desarrollando una constante tarea de investigación, enseñanza y creación en torno a las relaciones entre arte y tecnología. La inicial configuración de Ludion tomó prestado de Machado el término de "poéticas tecnológicas" como su objeto de estudio, para luego consolidarse durante los últimos años en torno a la más compacta denominación de tecnopoéticas. Basten estas menciones para dar cuenta de un verdadero "factor Machado" que se verifica como impulso a desarrollos altamente productivos tanto en la producción teórica como en la creación artística o el diseño realizados en la Argentina.

Dejamos para el final de este segmento que repasa el impulso promovido por sus ideas al único de sus libros publicado en España, que afortunadamente ha contado con buena distribución en el ámbito latinoamericano: El sujeto en la pantalla (MACHADO, 2009a). Es sintomático que dicho volumen haya sido publicado en Barcelona no en una colección de libros sobre cine, arte o comunicación, sino en una serie dedicada a la comunicación educativa. Su propuesta constituye una ejemplar muestra de la estrategia de Machado, empeñada en conectar campos que a veces son artificialmente divididos por fronteras disciplinares. Por cierto, catalogar un libro que comenzaba con un innovador análisis de Citizen Kane (1941), de Orson Welles, desde una teoría de la enunciación, y que luego revisaba las teorías del dispositivo cinematográfico, para continuar con reflexiones sobre la subjetividad en el ciberespacio y en las experiencias audiovisuales inmersivas, y finalmente asomarse a los horizontes del juego y la interactividad era un verdadero desafío. Pero la ligazón interna que urdía estas cuestiones transversales era de singular consistencia. Es preciso advertir el hilo conductor que sostenía la aparente diversidad de territorios, ya que existe a nuestro juicio una rigurosa lógica que relaciona esas distintas zonas de trabajo. 


\section{Líneas de fuerza en un campo en expansión}

En diversos pasajes del discurso de Machado puede leerse literalmente su intención de explorar ciertas líneas de fuerza, por ejemplo, cuando se aboca al estudio de la producción de videoarte en Brasil. Esas líneas de fuerza referían a campos, pero lo hacían en un sentido muy distante al que les asignaba Pierre Bourdieu, quien por otra parte era uno de sus destacados contrincantes. Aquí, las líneas de fuerza y los campos deberían ser entendidos más bien en el sentido en que James Faraday los planteó en sus pioneros estudios sobre electromagnetismo. Sin abusar del símil energético, podemos pensar que nuestro autor solía plantear sus exploraciones cartográficas, por ejemplo en el videoarte brasileño, a través de la detección de lo que esas líneas de fuerza dejaban organizar en un territorio en el que se alternaban lo incógnito y lo enmarañado. De esa manera, se permitía ejercer una mirada tan oblicua como productiva, ajena a los centramientos propios del especialista. En una reveladora conversación con el investigador chileno Iván Pinto, Machado aclaraba:

Yo no soy especialista en cine. Me parecía que había mucho dicho sobre eso ya que es la única área del audiovisual que tiene una tradición de crítica y pensamiento. Yo decidí primero irme hacia el video que me parecía algo distinto, que merecía análisis. Luego seguí hacia la televisión y los nuevos medios. (PINTO, 2010)

Así como investigar y curar no eran para Machado actividades divergentes sino complementarias, y hasta en cierto modo imbricadas una en otra, el desplazamiento desde la foto y el cine hacia las imágenes electrónicas y digitales le permitió indagarlas en forma oblicua. Y llegado el momento, trazar las conexiones necesarias, como cuando comenzó a trabajar de modo conjunto las tradiciones del cine experimental y del videoarte.

Por otra parte, dar cuenta de la intensa y significativa actividad de Machado como curador a lo largo de su trayectoria requeriría de por sí otro artículo. Tan solo destacaremos el impacto que su inspiración y publicaciones produjeron en los ámbitos curatoriales, tanto en la Argentina como en otros países de América Latina, como Chile, Perú, Colombia y México. En ese conjunto vale la pena remarcar el alcance inédito que comportó la muestra Visionarios, que integró hasta 2009 las selecciones de material de cinco curadores que cubrieron una inédita cantidad de países de América Latina y el Caribe, mapeando y hasta ensayando una periodización de la producción de cine experimental y videoarte en el continente. Ese fue un hito en la aspiración, largamente abrazada por Machado, de trascender las limitaciones 
de las historias de la creación audiovisual experimental arraigadas en los confines de cada nación. Así examinar las posibilidades de diálogo artístico, crítico y analítico en curso fue el objetivo del este proyecto, que reunió 73 obras, organizadas en nueve programas, y que abarcaba los países: Argentina, Bolivia, Brasil, Colombia, Cuba, Chile, Ecuador, México, Paraguay, Uruguay y Venezuela. Al ser una mixtura de investigación y curaduría, el proceso quedó a cargo de Machado como organizador y presentador de una antología histórica, mientras que los curadores regionales Elias Levin (México, América Central y Caribe), Jorge La Ferla (Argentina, Chile, Uruguay y Paraguay), Marta Vélez (Cuba, Ecuador, Bolivia, Colombia y Venezuela) y Roberto Moreira S. Cruz (Brasil) diseñaron el repertorio de un conjunto que itineró por diversas ciudades argentinas y pudo mostrarse en diferentes países, como Brasil, Bolivia, Chile, Perú y México. Una concisa descripción del proyecto fue publicada en el volumen compilado por Jorge La Ferla, Las prácticas mediáticas predigitales $y$ postanalógicas (MACHADO, 2008a).

En la primera década del siglo XXI, más allá de los textos citados, algunos ensayos de Machado han sido intensivamente leídos, citados y discutidos por sus planteos de punta. Destacamos, entre ellos, "Arte y medios: aproximaciones y distinciones" (MACHADO, 2004), que propone atravesar los límites de las máquinas semióticas y reinventar sus capacidades a partir de la intervención de su hardware y software. Cambiando los medios y sus finalidades preasignadas por otros horizontes de creación, con impronta flusseriana afirma:

Lo que hace, por lo tanto, un verdadero creador, en lugar de simplemente someterse a las determinaciones del aparato técnico, es subvertir continuamente la función de la máquina o del programa que él utiliza, es manejarlas en el sentido contrario de su productividad programada. (MACHADO, 2004, p. 86-87)

En ese sentido, es necesario recordar que también, durante esos años, Machado intervino con un potente planteo político sobre la creación artística en entornos tecnológicos, apelando a una actualizada y enriquecedora lectura de Flusser en clave política en "Tecnologia e arte contemporânea: como politizar o debate" (2005). Si bien no se trataba de un manifiesto, el ensayo incluía todo un programa de acción en torno a una política y una ética, fundado en quebrar mediante la intervención del arte el programa comandado por los aparatos (MACHADO, 2005).

Otro breve ensayo, reproducido en castellano en numerosas publicaciones electrónicas, que contó con notable impacto y difusión durante la última década 
y media fue "Convergencia y divergencia de los medios" (MACHADO, 2008b). El material circuló ampliamente después de su puesta en línea en 2006 por parte de la revista Miradas, de la Escuela Internacional de Cine de San Antonio de los Baños, donde lamentablemente no se encuentra hoy disponible, aunque sí se lo encuentra en otras publicaciones (MACHADO, 2008b).

La traducción de dichos textos, abundantemente replicados en la web a partir de distintas publicaciones académicas y culturales, precedió a su compilación brasileña en el tan breve como crucial volumen Arte e mídia (MACHADO, 2007a). Arte y medios, hibridación y convergencia, junto a su propuesta de una necesaria divergencia, son procesos de intersección, de transacciones y de diálogo; implican movimientos de tránsito, transición y provisionalidad en el devenir de los medios. También remiten a las tensiones de los elementos híbridos que actúan en sentidos convergentes, con partes que se desgarran y no llegan a fundirse completamente, en un paisaje mediático que nada se parece a un cuadro estático, sino un proceso en que la remediación y la reinvención marcan el paso.

En el mismo año en que se publicaba Arte e mídia (2007a) en Brasil, dentro del ya citado volumen El medio es el diseño audiovisual (MACHADO, 2007b), asomaba otro pequeño trabajo de Machado que constituye uno de los más lúcidos aportes a un tema de creciente auge en la creación audiovisual: "El film-ensayo".

Publicado originalmente en portugués en la revista Concinnitas del Instituto do Artes de la Universidad Estadual de Rio de Janeiro, el texto circuló en castellano a partir de su inclusión en el citado libro y también fue replicado en diversos medios electrónicos, constituyéndose en una contribución decisiva a la delimitación del campo multiforme del ensayo audiovisual, enunciada desde nuestras latitudes. Pero también es posible leer "El filme-ensayo" como manifestación de una línea de fuerza que recorre íntegramente el interior de la producción de Arlindo Machado y que, creemos, puede ser considerada como un hilo conductor que hilvana muchas de las dimensiones aparentemente divergentes y proliferativas de su trabajo intelectual. Allí expresaba de modo revelador algo que atañe tanto al objeto del artículo como a su propio itinerario intelectual:

Pensemos el filme-ensayo hoy. Puede ser hecho con cualquier tipo de imagen-fuente: imágenes captadas por cámaras, diseñadas o generadas en una computadora, además de textos obtenidos mediante generadores de caracteres, gráficos y también toda clase de materiales sonoros. Es por eso que el filme-ensayo supera largamente los límites del documental. Incluso puede usar escenas de ficción, tomadas en estudio con 
actores, porque su verdad no depende de ningún "registro" inmaculado de lo real, sino de un proceso de búsqueda e indagación conceptual". (MACHADO, 2007, p. 188-189)

Retomaremos lo expresado en esta cita en los últimos párrafos de este artículo, no sin antes dedicar unos párrafos al que es hasta hoy su último libro editado en la Argentina. Fue el caso de un volumen que, a pesar de la anacronía impuesta por las derivas editoriales, obtuvo un logro nada menor: el de la superación de esa delicada prueba de actualidad a la que se someten inexorablemente los libros que abordan el panorama comúnmente designado como de los "nuevos medios". El itinerario de la publicación en Argentina de Pre-cine y post-cine en diálogo con los nuevos medios digitales (MACHADO, 2007) fue toda una puesta a prueba de su capacidad su vigencia. La edición brasileña, editada en 1997, fue un hito no solamente por constituir un aporte decisivo para la instalación en nuestro continente del concepto de postcine en el debate académico e intelectual que se desplegaría con intensidad en la década siguiente, sino también por plantear un estudio de los medios y artes audiovisuales en tiempos largos, que no tuviera como eje el presunto "nacimiento" del cine en torno a los tiempos del Lumière Cinématographe y sus competidores durante la última década del siglo XIX. Si bien la propuesta de un precine ha despertado numerosas discusiones, que no es el objeto de análisis de este artículo, pero que se orientan mayormente a objetar su apreciación teleológica de una serie de fenómenos muy diversos, que exploraban distintos espectáculos y tecnologías del audiovisual durante las centurias previas. A Machado el término le permitió elaborar una refinada arqueología de las máquinas de visión y audición desde el Renacimiento y que le hizo necesario, en algunos puntos, remontarse a las experiencias paleolíticas. Para un volumen dedicado a examinar ciertas conexiones entre imágenes técnicas localizadas a lo largo de toda la historia de la humanidad y ciertas tendencias recientes de los nuevos medios, el riesgo de quedar desactualizado en poco tiempo es patente; y para asumirlo frontalmente: los nuevos medios de los 1990 ya son obsoletos veinte años más tarde.

No obstante, la edición argentina pudo ser leída y fue productiva en el 2015 con un insólito efecto de contemporaneidad. Aunque la bibliografía y los casos de producción artísticas analizados se limitaban a la primera mitad de los años 1990, no solamente se sostenían de manera admirable los planteos sobre el precine, sino que las líneas de fuerza observadas en plena transición desde un universo de imágenes electrónicas de carácter analógico hacia otro signado por el procesamiento y la generación numérica mantenían intacta su capacidad elucidatoria. 
Solamente faltaban, por razones obvias, los aportes y discusiones suscitados en el siglo XXI por el concepto de postcine, pero fue posible comprobar que la difusión de este libro en castellano permitió presentar al lector a ese público ni más ni menos que otro joven clásico de la teoría audiovisual en nuestro continente (MACHADO, 2015).

Volvamos, para finalizar, al asunto del film-ensayo. En la ya mencionada conversación con Iván Pinto, sostenida justamente durante la visita que Machado realizó a Chile acompañando a la muestra Visionarios, declaraba Machado:

Yo tengo un proyecto pendiente de hablar de las imágenes como una forma de conocimiento. Eso es una cosa que aprendí con Eisenstein, que creía que en la era de las imágenes una manera de escribir sería a través del cine, a través de las imágenes y los sonidos. Y de alguna manera eso terminó concretizándose de la mano de cineastas como Chris Marker, Jean-Luc Godard, Alexander Kluge. Que son filósofos, son pensadores, pero que no escriben libros, hacen películas. Y las películas pueden ser entendidas como una manera en la que la filosofía se construye hoy, como el pensamiento se construye hoy. Entonces mi idea es retomar ese camino de las imágenes inteligentes, imágenes del pensamiento. (PINTO, 2010, s.p.)

Lo que allí evocaba, sin duda, era un proyecto cuya extensión era la de una vida intelectual entera. Al recorrer las líneas de fuerza del itinerario de Machado, con sus reconocidas incursiones en el campo de la creación fotográfica, sus experiencias en el cortometraje y obras multimediales, sus libros electrónicos en distintas arquitecturas y formatos y las publicaciones en formato papel que aquí hemos comentado, la decantación de su pensamiento en nuevas formas audiovisuales era no solamente una perspectiva viable, sino una prosecución lógica de su empresa. Su desaparición física y el importante volumen de sus trabajos aún no traducidos al castellano nos convoca al desafío de seguir extendiendo su legado. Se trata, en definitiva, de proseguir interrogando lo que en sus propias palabras era ese camino tantas veces desestimado por persistentes prejuicios, pero cada vez más necesario de recorrer: el de las imágenes inteligentes, esas imágenes del pensamiento que supo vislumbrar de modo ejemplar.

\section{Referencias}

BASTOS, M. "O pensamento de Arlindo Machado e uma genealogia das artes do vídeo no Brasil”. Significação: Revista de Cultura Audiovisual, São Paulo, v. 48, n. 56, p. 33-53, 2021.

LA FERLA, J. (comp.). Video Cuadernos VI. Textos de Arlindo Machado. Buenos Aires: Nueva Librería, 1994. 
MACHADO, A. "Videos y lenguajes". In: LA FERLA, J. (comp.). Video Cuadernos I. Buenos Aires: Nueva Librería, 1991. p. 55-62.

MACHADO, A. "El imaginario numérico: simulación y síntesis". Acta Poética, Ciudad de México, v. 13, n. 1-2, p. 55-76, 1992.

MACHADO, A. "El imaginario numérico: simulación y síntesis". In: LA FERLA, J. (comp.). Video Cuadernos VI, Buenos Aires: Nueva Librería, 1994. p. 75-92.

MACHADO, A. "Múltiples ventanas de Sandra Kogut". In: LA FERLA, J. (comp.). Video Cuadernos III. Buenos Aires: Nueva Librería, 1993. p. 19-32.

MACHADO, A. "El advenimiento de los medios interactivos". In: LA FERLA, J.; GROISMAN, M. El medio es el diseño: estudios sobre la problemática del diseño y su relación con los medios de comunicación. Buenos Aires: Oficina de Publicaciones del CBC; Universidad de Buenos Aires, 1996a. p. 15-24.

MACHADO, A. "El imaginario numérico". In: LA FERLA, J.; GROISMAN, M. El medio es el diseño: estudios sobre la problemática del diseño y su relación con los medios de comunicación. Buenos Aires: Oficina de Publicaciones del CBC; Universidad de Buenos Aires, 1996b. p. 31-46.

MACHADO, A. "Técnicas de la fotografía: la síntesis numérica”. In: LA FERLA, J. (comp.). La revolución del video. Buenos Aires: Libros del Rojas, 1996c. p. 65-74.

MACHADO, A. "Dos o tres cosas sobre Eder Santos". In: LA FERLA, J. (comp.). Contaminaciones: del videoarte al multimedia. Buenos Aires: Libros del Rojas, 1997a. p. $94-99$.

MACHADO, A. "El arte del video en el Brasil". In: LA FERLA, J. (comp.). Contaminaciones: del videoarte al multimedia. Buenos Aires: Libros del Rojas, 1997b. p. $137-140$.

MACHADO, A. "El arte del video en Brasil". In: LA FERLA, J. (comp.). Medios audiovisuales: ontología, historia y praxis. Buenos Aires: Libros del Rojas, 1999. p. 122-142.

MACHADO, A. El paisaje mediático: sobre el desafío de las poéticas tecnológicas. Buenos Aires: Libros del Rojas, 2000a.

MACHADO, A. "Por un arte transgénico". In: LA FERLA, J. (comp.). De la pantalla al arte transgénico. Buenos Aires: Libros del Rojas, 2000b.

MACHADO, A. "Repensando a Flusser y las imágenes técnicas". In: LA FERLA, J. (comp.). Cine, video, multimedia: la ruptura de lo audiovisual. Buenos Aires: Libros del Rojas, 2001. p. 71-83. 
MACHADO, A. "Arte y medios: aproximaciones y distinciones". La Puerta, La Plata, n. 1, p. 84-93, 2004.

MACHADO, A. "Tecnologia e arte contemporânea: como politizar o debate". Revista de Estudios Sociales, Bogotá, n. 22, p. 71-75, 2005.

MACHADO, A. Arte e mídia. Rio de Janeiro: Zahar, 2007a.

MACHADO, A. "El filme-ensayo". In: LA FERLA, J. (comp.). El medio es el diseño audiovisual. Manizales: Ediciones Universidad de Caldas, 2007b. p. 183-190.

MACHADO, A. "Voces y luces de un continente desconocido". In: LA FERLA, J. (comp.). Artes y medios audiovisuales: un estado de situación II. Las prácticas mediáticas predigitales y postanalógicas. Buenos Aires: Aurelia Rivera, 2008a. p. 368-375.

MACHADO, A. "Convergencia y divergencia de medios". In: PEREIRA GONZÁLEZ, J. M.; VILLADIEGO PRINS, M.; SIERRA GUTIÉRREZ, L. I. (coord.). Industrias culturales, músicas e identidades: una mirada a las interdependencias entre medios de comunicación, sociedad y cultura. Bogotá: Siglo del Hombre, 2008b. p. 73-88.

MACHADO, A. El sujeto en la pantalla: la aventura del espectador, del deseo a la acción. Barcelona: Gedisa, 2009a.

MACHADO, A. El paisaje mediático: sobre el desafío de las poéticas tecnológicas. 2. ed. Buenos Aires: Nueva Librería, 2009b.

MACHADO, A. Pre-cine y post-cine en diálogo con los nuevos medios digitales. Buenos Aires: La Marca, 2015.

PINTO, I. "Un pensamiento de las imágenes: conversación con Arlindo Machado". Revista La Fuga, Santiago de Chile, invierno 2010. Disponible en: https://bit. ly/3tli5mn. Acceso el: 6 en. 2021.

RUSSO, E. A. "Prólogo". In: MACHADO, A. El paisaje mediático: sobre el desafío de las poéticas tecnológicas. Buenos Aires: Libros del Rojas, 2000.

SANTAELLA, L. "Pensamiento crítico en ação". Significação: Revista De Cultura Audiovisual, São Paulo, v. 48, n. 56, p. 20-32, 2021.

sometido el: 12 nov. 2021 | aprobado el: 20 dez. 2021 